Lyons globe:-I. The Geography of Ptolemy; 2. The "Portuguese Asia" of De Barros (1552); 3. The "Description of the Congo," by Pigafetta, according to Lopez (I 592); 4. The "Historical Description of Ethiopia" of Dom Francesco Alvarez" (1558); 5. The "Africa" of Leo Africanus (1556); 6. And the old maps and portulans.

Among these old maps and portulans, those which appear at this period to have had a certain influence are :- 1 . The Medicean Portulan (135 I); 2. The Catalan Atlas (1375); 3. The Map of Mecia de Viledestes (1413); 4. The Map of Johannes Leardus (I448) ; 5. The Mappemonde of Fra Mauro; 6. The Ambrosean Map (1480); 7. The Mappemonde of Juan de la Cosa (1500); 8. The Map of Diego Ribera; 9. The Spanish Mappemonde of the National Library, Paris (Fig. 3) (I540); Io. The
Maps of Ramusio, of Pigafetta, and of Hugues Linschoten.

In the detailed report which the Lyons Commission will communicate to the Society will be shown to what extent each of the above documents contributed to the establishment of the Flemish maps, on which probably the Lyons globe was more immediately based. The same Report will contain an investigation into the travels known or unpublisbed which, from the tenth century, have contributed to the progress of the African geography of the Middle Ages and of the Renaissance. This investigation will include the following:-I. The Arab voyages and Compendia; 2 . The voyages of the mendicant Spanish friar of the fourteenth century; 3 . The expedition of eight dominicans of Montpellier to the sources of the Nile (1317-1350), unpublished; 4. The travels of

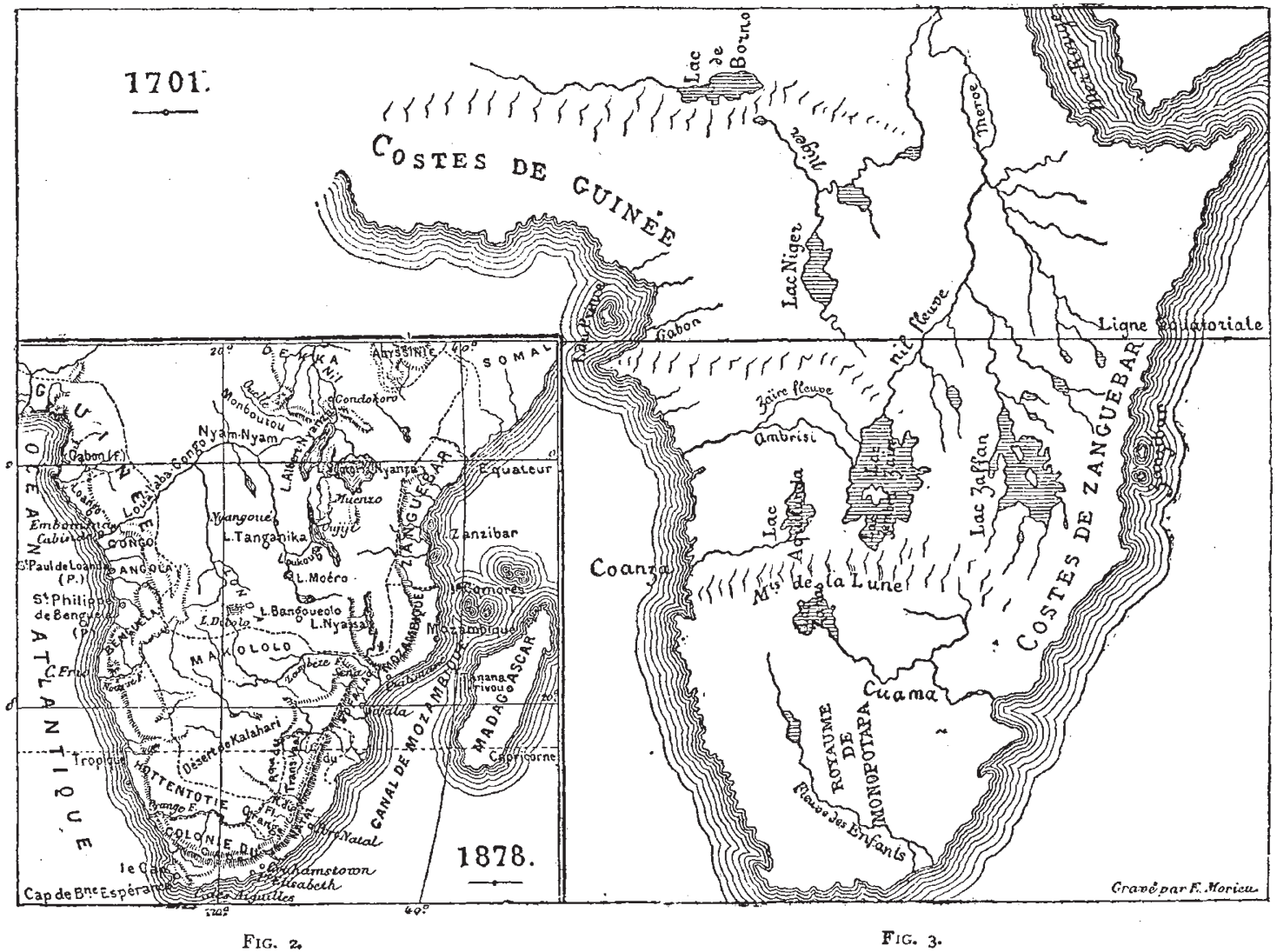

FIG. 2.-Map of Stanley's Recent Journey Across Africa. FIG. 3.-Portion of a Globe of 17or, belonging to the Lyons Library, from a copy by M. Deloncle.

the brothers Vivaldi, thirteenth century; 5. The expedition of the Catalan Ferrer in 1346 , unpublished; 6. The royages of Diego Cam; 7. The itineraries of the early pombeiros; 8. The "Eastern Ethiopia" of Joan dos Santos; 9. The travels of Barbosa; Io. The exploration of the Dutch Jan van Herder, in the country of the Akkas, unpublished; II. The Derrotero desde Lisbõa Al Cabo de Bueno Esperanza y India Oriental, anonymous and unpublished; 12. The description of the Congo, by Martinus Abarca de Boléa et Castro (I6or), unpublished; I3. The "Universal Book of the Navigations of the World" (1590?), Spanish, unpublished; I 4; The Travels of the Belgian Pierre Farde from Alpiers to the Congo (1686), unpublished; I5. The "Travels of Manoël Godinho" (I663); 16. The Letters of Father Mariano, the Jesuit, on Kaffraria, \&c., \&c.

The work undertaken by the Lyons Geographical
Society is creditable to them in the highest degree and will result in a valuable addition being made to historical geography. Their work, as the Commission rightly maintain, is to some extent international, and deserves the countenance and assistance of geographers all the world over.

\section{COSMIC METEOROLOGY}

II.

TNFLUENCE of the Moon on the Earth's Magnetism.There is a fact in connection with the moon's influence on our earth for which an explanation is necessary, and $\mathbf{M}$. Faye has proposed for this end a hypothesis in advance. $\mathrm{He}$ had already pointed out Dr. Lloyd's investigation which showed that the diurnal magnetic variations could $x$ Continued from p. 28 . 
not be explained by the hypothesis that the sun acts as a magnet. But, it is said, "May the moon not acquire induced magnetism under the action of the earth, perpetually variable according to the relative position of the two bodies? If we consider the enormous magnetic power of the earth, that Gauss finds equal to that of 464 trillions $^{1}$ of magnets weighing a pound each, and if we remark besides that the distance of the moon to the earth does not exceed thirty times the length of this gigantic magnet, we may give an affirmative answer to the question proposed. But then the magnetism induced in the moon should in its turn exercise a small action upon the proper magnetism of the earth in the period of a lunar month. The observations alone can decide this provided they are of great precision."

M. Faye then cites the results obtained from the Toronto observations by Gen. Sir E. Sabine, that for the magnetic declination showing a range of $\mathrm{o}^{\prime} \cdot 64$; and he adds, "All these effects are of double period; they show two maxima and two minima in the course of the lunar month of $29 \frac{1}{2}$ days, which proves that they are due to an induced or reflex action, not to a direct action of the moon herself." I shall put my remarks on this subject under three heads.

I. Is such a result possible for the moon's synodical revolution? Let us commence with full moon at the winter solstice; near this epoch the moon is in the plane perpendicular to the ecliptic passing through the earth's magnetic axis and the sun. The north pole of the terrestrial magnet is then presented to the moon in such a way as to produce the maximum of induction; when the moon is near her third quarter the two terrestrial magnetic poles will be equidistant from the moon and the inducing action will be a minimum; there will be a second maximum near new moon when the south pole is most presented to our satellite and a second minimum near the first quarter. If now we follow the earth in her revolution to the vernal equinox, we shall find all this changed. At full moon our satellite is then equidistant from the two terrestrial poles, and the inducing action is a minimum; it is a maximum, on the contrary, near the first and third quarters. The consequence will be that if any inducing action existed it would have the same value at all ages of the moon in the mean of observations made during a series of years, such as were employed by Sabine for the variations in question. Such a result, however, as has been imagined by M. Faye might be possible if, instead of the synodical, we employ the tropical revolution of the moon, which occupies nearly 27.3 days.

2. We may inquire, then, if the moon as a permanent or induced magnet can produce any magnetic variations appreciable by our instruments? In the first place, Mr. Stoney has shown that if the moon were as magnetic bulk for bulk as our earth, her whole action in deflecting a freely-suspended needle in our latitudes, could not exceed one-tenth of a second of $\operatorname{arc}\left(\mathrm{O}^{\prime \prime} \cdot \mathrm{I}\right) .^{2}$ In order to consider the question of the variable magnetism induced in the moon by our earth, let us suppose her inductive capacity equal to that of cast-iron. From Barlow's experiments at Woolwich with iron balls I find that the magnetism induced in an iron ball of one foot diameter is about $2^{\circ} \mathrm{O}$, in English units, which is nearly twice the magnetic force given by Gauss for the same volume of our earth. Barlow found the induced moments of different balls to vary as their volumes, and assuming that the induced magnetism varies inversely as the cube of the distance of the inducing and induced bodies, we find at the moon's distance (60 terrestrial radii) the induced magnetism at the maximum, under the most favourable condition, could not be more than $\frac{2}{60^{3}}=\frac{I}{108,000}$ of that supposed in the first case,

M. Faye uses the word trillions, but the trillions are English, not French, he latter being a very different number.

2 Phil. Mlag., vol, xxii. p. 294 that is when as magnetic as the earth. Her whole action on a magnetic needle here, then, due to the earth's induction, could not exceed one millionth of a second of arc. It is advantageous to get rid of hypotheses which are so completely insufficient, and we may put aside for the future any consideration of the moon's action by her own permanent magnetism, or by a variable magnetism induced in her by the earth.

3. M. Faye has also misunderstood the facts which he wished to explain. The results obtained by Sabine have reference to a variation which occurs in $24^{\frac{3}{4}}$ hours, the lunar day, and not the lunar month of $29 \frac{1}{2}$ days. The laws of the lunar diurnal variations were obtained first by Kreil for the magnetic declination, and by myself for the magnetic force and inclination. This action of the moon is, however, so very different from what is generally supposed, and from what was concluded from the first inves gation on the subject, that it is of the greatest importance, in relation to the whole question of cosmic meteorology, I should state some of the more marked facts which have been deduced from eleven years' hourly observations on the magnetic equator. I shall limit myself at present to the lunar actions on the direction of the horizontal magnetic needle.

The moon, in a lunar day of 24.7 hours, produces a variation in the earth's magnetism, such that the magnetic needle makes two complete and nearly equal oscillations from an easterly to a westerly position in the interval in question. This is the general mean law. We have seen, in considering the law of the solar diurnal variations that, near the magnetic equator, the law becomes reversed when the sun passes from the one hemisphere to the other, so that when the sun is north, the movement of the needle is like that in high north latitudes, and when south, like that in high south latitudes. If, then, the moon acts in the same way as the sun, we should expect a similar phenomenon for the lunar diurnal variation when the moon crosses the equator. This is not the fact. The law differs little for the position of the moon north and south of the equator.

There is, however, an inversion of the lunar diurnal oscillations; thus, in the months of December and January the north end of a magnetic needle is farthest east when the moon is on the upper and lower meridians, and farthest west near moon-rise and moon-set; whereas in the months of June and July the reverse is the case, the north end of the needle being farthest west when the moon is on the meridian (upper and lower) and farthest east when she is on the horizon. It followed from this, as for the solar diurnal law, that the oscillations should be in opposite directions at the same time in the higher latitudes of the two bemispheres, as has been found to be the case.

It is not then when the moon crosses the equator but near the times when the sun does so, that the moon's action is reversed.

The dependence of the lunar action on the position of the sun becomes more evident as the investigation becomes more detailed. When we determine the mean law for each month of the year, we find that the north end of the needle moves equally far east and equally far west at each of the two oscillations in the lunar day; this is not found to be the case for different positions of the moon relatively to the sun. Thus in the quarter lunations including full moon, in the months of December and January, the greatest west-east-west oscillation of the needle occurs when the moon is on the lower meridian; not when the moon, but when the sun, is shining on the place of the needle. The oscillation from moon-rise to moon-set, that is to say, while the moon is above the horizon, is little more than one-third of the oscillation for the half day when she is below the horizon; the two westerly extreme positions when the moon is on the horizon are nearly the same. 
Similar results are obtained for the other quarter lunations. In all cases that oscillation is the greatest of the two for which the sun is above the horizon, whether the moon be above it or not.

There are still some remarkable facts connected with this variation at the magnetic equator. Limiting our examination of them always to December and January, we find, if we determine the oscillations due to the moon for the day when she is in conjunction and for each of the six following days, that in the first three days of the seven the oscillation is west-east-west during the day, that is, from sunrise to sunset; and in the last three days it is east-zest-east. In the middle day of the seven the lunar action is almost null; the oscillation of the needle is very small, as we might expect, since on that day the change at sunrise from a west-east to an east-zest motion takes place. The lunar hours of the maximum and minimum extremes thus oscillate about two hours on each side of the mean, depending on the position of the moon at sunrise.

The action of the moon, then, is dependent on the sun's position relatively to the equator (or the earth's position in its orbit), and on the position of the moon relatively to sunrise and sunset. But there is no relation between the laws and amplitudes of the solar and lunar diurnal oscillations. In the months from which I have taken my illustrations, the solar diurnal variation is a single oscillation: that for the moon, however taken, for single days, for quarter or for whole lunations, is always double. Through the combination of all the varying modes in which this oscillation is produced from day to day, the mean for a lunation is a regular double oscillation. The amplitude of this mean oscillation is three times as great in January as in June or July; whereas the amplitude of the mean solar diurnal variation is a half greater in June or July than in January.

I sball add another fact, one of the greatest importance in connection with this subject. We bave seen that the lunar diurnal variation changes in the relative amplitudes of the two oscillations from day to day; the consequence of this is that when the means for a whole lunation, or even a quarter lunation, are taken, the mean amplitude is much less than that which is shown by each day separately. Thus I have found that the range of the mean lunar diurnal oscillation for the lunation December I6, I 858 , to January I 5 , I 859, at Trevandrum, was I'25, while the ranges of the mean oscillations for the quarter lunations varied from $I^{\prime} 70$ to $2^{\prime} \cdot 70$, these quarter lunations giving exactly the same laws as have been deduced from eleven years observations for the same lunar epochs.

In order to understand the value of these results we must compare them with the ranges of the solar diurnal oscillations for the same months; those for December, I 858 , and January, 1859 , were $2^{\prime} \cdot 20$ and $2^{\prime} \cdot 24$ respectively. And as on some days the lunar diurnal variation has amounted to nearly $5^{\prime} \circ$ (which is equivalent to $12^{\prime}$ in England with the smaller directive force), it appears that the lunar action is sometimes greater than the solar action at the magnetic equator.

As long as the lunar diurnal action was considered to be of the minute character first discovered, it was always possible for the supporters of the heat thesis to suspect that some small unknown heat action was in question. Such an idea is no longer possible. The lunar is sometimes greater than the solar diurnal action; and the former is dependent for its magnitude on the light and heat vibrations due to the sun shining on the place of the magnetic needle. ${ }^{1}$

If the solar light and heat vibrations can increase the magnetic action, there can be no difficulty in believing

* Mr. Willoughby Smith's experiments show that the light vibrations of the ether in selenium diminish in a very marked manner the electrical resistance of the crystal; and it does not seem improbable that the increase of the lunar magnetic oscillation in sunlight may be due to some similar action. that these vibrations may in their turn suffer some modification of intensity. It would be difficult to measure small variations of the sun's light with sufficient accuracy as yet, though Mr. Willoughby Smith has suggested a selenium photometer for this end; we can, however, measure the variations of temperature, and the fact that the direct heating action of the moon is inappreciable is no longer sufficient to disprove the results of Mädler, Kreil, Park Harrison, and Balfour Stewart. We have in fact a mode of lunar action with which M. Faye was unacquainted and could not take into account. The whole basis of his argument is therefore destroyed.

The view now given opens up a wide field of inquiry, and cosmic meteorology appears under another aspect. I hope to be able at another time to present other facts which seem to relate to magnetical and meteorological phenomena.

JOHN ALLAN BROUN

\section{THE NUTRITION OF DROSER.A ROTUNDI- FOLIA}

DURING the summer of 1877 I began an experimert, the results of which were given in a paper read before the Linnean Society, January 17, 1878. A number of Drosera Plants were freely supplied with meat, while another set were kept without animal food. At the end of the season the two sets were compared in various ways with the object of deciding whether or not carnivorous plants profit by an animal diet. In the abstract of my paper published in NATURE (vol. xvii. p. 222), it may be seen how numerous were the advantages gained by the fed plants.

The further results of the experiment are not without interest.

The plants on which I worked were cultivated in six soup-plates, and after all the flower stems had been cut, the plants in three of the plates were removed from the moss in which they grew, and were counted and weighed. The plants in the other plates were left undisturbed with the object of comparing the new plants which should spring up from the winter buds of the two sets in the following year. They were removed to the hothouse in the course of the autumn, in order that they might rapidly send up the next year's leaves. By the middle of January, 1878 , it became quite clear that far more leaves were springing up from the winter buds of the plants which had been fed than from the others. Both sets of plants were now kept without food, and on April 3 they were removed from the plates, and carefully counted, dried, and weighed. The following numbers give the result of the examination :-

\begin{tabular}{|c|c|c|c|c|}
\hline & \multicolumn{2}{|c|}{$\begin{array}{l}\text { Actual numbers and } \\
\text { weights. }\end{array}$} & \multicolumn{2}{|c|}{$\begin{array}{l}\text { Proportion between } \\
\text { two first coliumns. }\end{array}$} \\
\hline & Not fed. & Fed. & Not fed. & Fed. \\
\hline Number of plants ... ... & 89 & 105 & 100 & 1180 \\
\hline Total weight $\ldots \quad \ldots \quad \ldots$ & $\begin{array}{l}\text { grams. } \\
\cdot 206\end{array}$ & $\begin{array}{l}\text { grams. } \\
\cdot 518\end{array}$ & 100 & $25 \mathrm{I} \cdot 6$ \\
\hline Average weight per plant & $\cdot 0023$ & $\cdot 0049$ & 100 & $213^{\circ} \mathrm{O}$ \\
\hline
\end{tabular}

It will be seen that there is only comparatively a small difference (I 8 per cent.) between the number of not-fed and fed plants. Numerous minute offsets were found among both sets, and were all counted as separate plants. But, judging either by the total or average weights, no doubt can be entertained of the great advantage gained by the fed plants. It is a striking fact that, in spite of the far larger yield of flower stalks, seeds, \&c., produced during the previous summer by the fed plants, they were nevertheless enabled to lay by a far greater store of reserve-material than their not-fed competitors. 